\title{
A novel technique for mitomycin-c application in frontal sinus surgery*
}

\author{
I. Konstantinidis, A. Chatziavramidis, J. Constantinidis \\ 2nd Academic ORL Dept, Papageorgiou Hospital, Aristotle University, Thessaloniki, Greece
}

Rhinology 52: 276-280, 2014

DOI:10.4193/Rhino13.060

*Received for publication:

May 20, 2013

Accepted: January 31, 2014

\begin{abstract}
Objective: Local application of mitomycin-c (MMC) seems to be effective in reducing adhesions and stenosis after FESS. However this is not clearly seen in frontal sinusotomy. This study assesses the effectiveness of local MMC in the frontal ostium using a foamy material (otowick) and compared with cottonoids.
\end{abstract}

Methods: Forty-seven patients with chronic rhinosinusitis without polyps enrolled in this study. Two subgroups were studied: one with MMC application in one nostril using cottonoids and a second with MMC injected in an otowick. In all patients MMC was applied twice, intraoperatively and 4 weeks later. In both groups normal saline was applied to the other nostril on the same material with the MMC side. Six months postoperatively all patients were assessed endoscopically by a clinician blinded to the MMC side.

Results: Overall, MMC application was more effective than normal saline in both groups. Otowick use presented favorable initial results especially in primary cases regarding ostium patency, and need for revision surgery. The use of MMC cottonoids did not show any benefit in primary cases.

Conclusion: The described technique seems to be effective in maintening frontal ostium patency as it provides a more precise and deeper drug delivery to this area.

Key words: mitomycin-c, frontal sinus, stenosis, chronic rhinosinusitis, surgical revision

\section{Introduction}

Postoperative adhesions and ostium stenosis are common causes of functional endoscopic sinus surgery (FESS) failure

$(1,2)$. Granulation and scar tissue formation during the healing process can lead to persistent symptoms due to decreased sinus ventilation and mucus drainage. The complex anatomy of frontal recess makes the patency of frontal sinusotomy one of the most difficult aspects of FESS. Many studies showed that postoperative frontal ostium stenosis rated between $20-25 \%$ of patients ${ }^{(3-5)}$. The maintenance of a patent ostium is a significant factor for a successful operation and for this purpose many techniques have been developed, including local application of mitomycin-c (MMC).

MMC is an antibiotic-antineoplasmatic agent mainly used in chemotherapy of certain types of cancer. However, its local application in the nose has been shown to reduce scar formation via inhibition of fibroblasts proliferation ${ }^{(6)}$. Although increasing evidence exists regarding its positive effect on antrostomy patency after FESS, similar results were not clearly seen in the frontal sinus ostium ${ }^{(7)}$. This could be attributed to the use of neurosurgical cottonoids for local MMC application in the majority of studies ${ }^{(8,9)}$. The above technique applies the drug in the surface of the operated middle meatus, however this presents certain limitations regarding the frontal sinus ostium. Owning to its shape, a deeper application of the drug is needed. The necessity for a material, which offers deeper and equal application of MMC in an "hourglass" shaped area, led our team to assess the efficacy of an otowick into the frontal ostium, in which MMC was injected. 


\section{Materials and methods}

Patient population

In total 47 patients with chronic rhinosinusitis and bilateral frontal sinuses involvement enrolled in this sequential, cross-over study. Data were collected from the clinical notes of patients who failed maximal medical treatment and had undergone bilateral primary or revision FESS.

Patients with not an equal extent of the disease in both sides (difference in Lund-Mackay CT score > 2) and/or pathology like nasal allergic fungal sinusitis and nasal polyposis were excluded. All patients provided written informed consent according to a protocol approved by the Ethic Committee of the Aristotle University and the Helsinki Declaration for human subjects.

Patients' files with indication for surgery were stored in a secure password-protected database. Allocation concealment was performed by a secretary using blocked randomization (block size: four patients) for the two study groups (cottonoids vs otowick) by means of FileMaker Pro 11 Software (FileMaker Inc, Santa Clara USA).

\section{Surgery}

Although the extent of the sinus disease determined the extent of surgery for each patient, all patients in the study group underwent at least frontal sinusotomy and anterior ethmoidectomy according the Messerklinger principles. In patients where a deviated septum limited the access to the middle meatus, an endoscopic septoplasty was performed. Conventional instrumentation was used in all cases.

The frontal recess was dissected with agger nasi cells opening, preservation of the mucosa as much as possible and meticulous removal of bony remnants. The frontal sinus ostium was visualized with a 30 degree endoscope and its patency was confirmed with the use of a curved Frazer suction number 8 (diameter 2.67 $\mathrm{mm})$.

The ostium was considered as patent when suction could pass without any forceful movement, a fact which practically means that the ostium's size is $\geq 3 \mathrm{~mm}^{(7)}$.

\section{MMC treatment}

At the end of the surgical procedure, $1 \mathrm{ml}$ of a $0.5 \mathrm{mg} / \mathrm{ml} \mathrm{MMC}$ solution was applied for 5 minutes in a randomized order onto the frontal ostium of one side and normal saline on the other side. Patients were divided in two groups with equal sex and age distribution. In the first study group, MMC application performed using soaked neurosurgical cottonoids and for the second group a $6 \mathrm{~mm}$ in length piece of an otowick (Merocel, Xomed Surgical Products Inc., Jacksonville, USA) was used (Figure 1). This size was chosen to cover the variability in frontal sinus ostium length ${ }^{(10)}$. The otowick was placed into the frontal ostium and then MMC was injected. When the MMC solution is injected into the otowick, it reshapes from cylindrical to hourglass co-
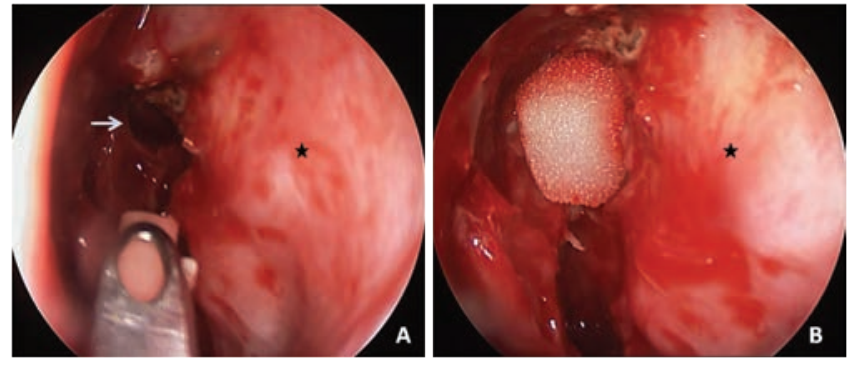

Figure 1. Endoscopic view of a left nasal cavity A. Otowick placement with a curved blakeslay forceps and B. Saturated otowick placed into the frontal ostium at the end of the operation (The asterisk indicates the lateral nasal wall and the white arrow the frontal sinus ostium).
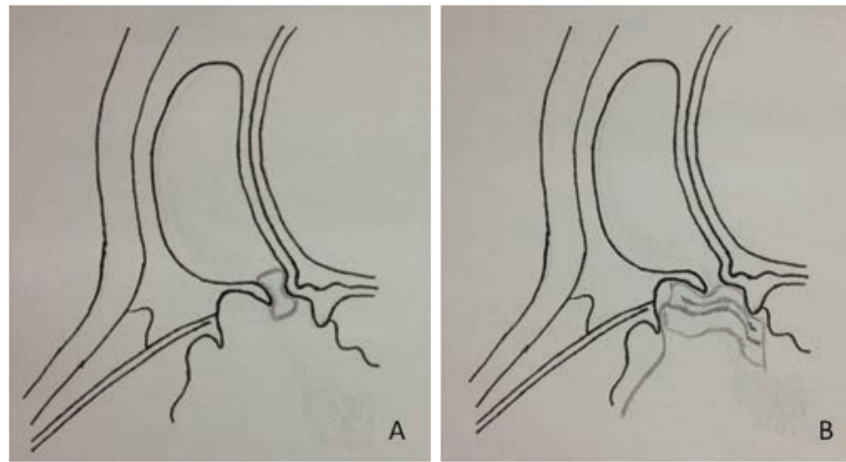

Figure 2. Schematic representation of a patent frontal sinus after anterior ethmoidectomy and frontal sinusotomy A. application of an otowick into the ostium. Following the MMC injection the otowick takes an hourglass shape covering all the area of interest. B. Use of MMC saturated cottonoids covers only partially the ostium.

vering equally all the area of surgical interest (Figure 2 ). We did not use a cottonoid into the frontal ostium as its contact with an hourglass area cannot be standardized especially with the upper part. In both groups the same material was used in the control side as in the MMC side.

Then cottonoids and otowicks were removed and the nasal cavities were irrigated with sterile normal saline. All patients were discharged with a 10-days course of oral antibiotics, nasal steroids for 4 weeks and instructions for saline irrigation of the nose for up to 2 months.

Four weeks later, a second application of $1 \mathrm{ml}$ of a $0.5 \mathrm{mg} / \mathrm{ml}$ MMC solution was performed with the same technique after debridement of the nose at an outpatient setting (Figure 3). Specifically, MMC was applied on the same side as in the operation using the same material (cottonoids or otowick). Final measurements performed at a 6 months postoperative follow-up assessment. At this appointment, a blinded observer regarding the MMC application side, performed nasal endoscopy with a 


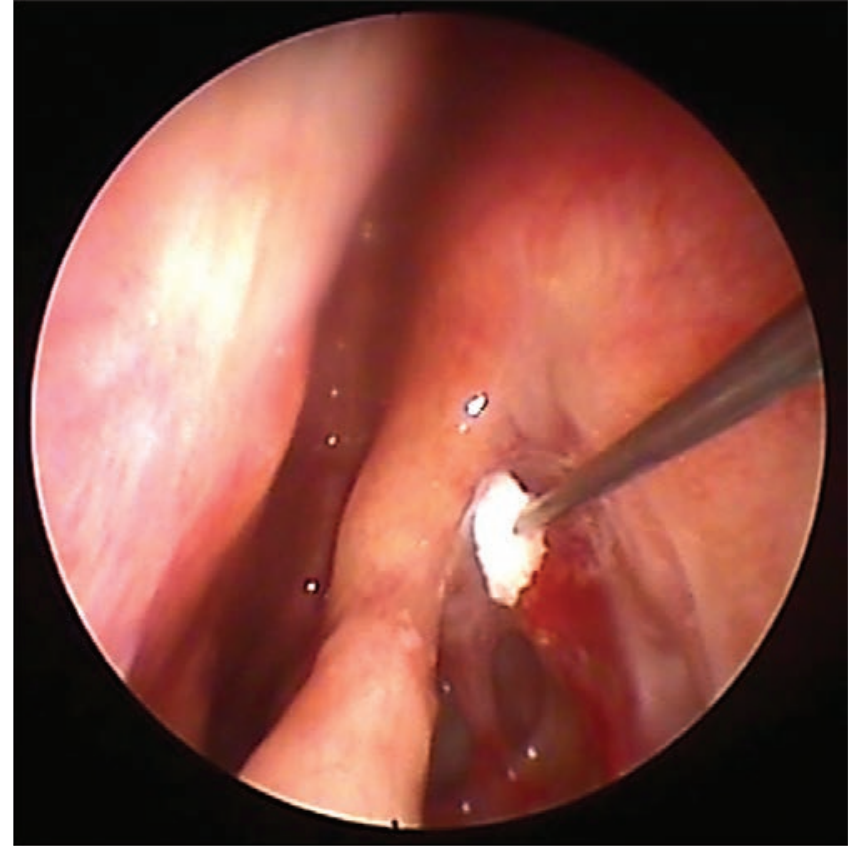

Figure 3. Endoscopic view of postoperative MMC otowick application at 4 weeks follow-up appointment. This procedure performed at an outpatient setting.
Table 1. Percentages of frontal ostium stenosis within the study groups. ( $n=$ number of patients). The asterisk symbolizes significant differences. A comparison cannot be performed for revision surgery due to small sample size (ND = not determined).

\begin{tabular}{|c|c|c|c|}
\hline & Overall & $\begin{array}{l}\text { Primary } \\
\text { surgery }\end{array}$ & $\begin{array}{l}\text { Revision } \\
\text { surgery }\end{array}$ \\
\hline & $(n=19)$ & $(n=11)$ & $(n=8)$ \\
\hline \multirow[t]{4}{*}{$\begin{array}{l}\text { Mitomycin-c, } \\
\text { cottonoid application }\end{array}$} & $21 \%$ & $20 \%$ & $22 \%$ \\
\hline & $26.3 \%$ & $20 \%$ & $33 \%$ \\
\hline & $p=0.04^{*}$ & no difference & ND \\
\hline & $(n=20)$ & $(n=12)$ & $(n=8)$ \\
\hline $\begin{array}{l}\text { Mitomycin-c, } \\
\text { otowick application }\end{array}$ & $10 \%$ & $8.3 \%$ & $12.5 \%$ \\
\hline Control side & $30 \%$ & $25 \%$ & $37.5 \%$ \\
\hline Significance & $p<0.001^{*}$ & $p<0.001^{*}$ & ND \\
\hline
\end{tabular}

300 degree endoscope for the assessment of frontal ostia. Their patency confirmed with the same curved Frazer 8 suction.

\section{Statistical analysis}

Statistical analysis was performed using SPSS version 16.0 for Windows (SPSS Inc., Chicago, IL, USA). Sample size calculation was based on the following parameters: acceptable error alpha: 0.05, acceptable error beta: 0.10, clinical difference: $3 \mathrm{~mm} / \mathrm{SD}$ \pm 2.5 . The adequate minimum number of patients for a study with $80 \%$ power according to Douglas Altman's nomogram is 11 self-controls patients (22 nasal cavities) for each group. Descriptive statistics are presented within the body of the text as mean values \pm standard deviation of means (SD). Comparison of the frontal ostium patency between groups was performed with the Mann Whitney u test. Statistical significance level was set at 0.05 .

\section{Results}

In total 25 men and 22 women were enrolled in this study (mean age, 51.7 years; range, 31-68 years).

\section{Ostium patency}

At a 6 months follow-up appointment, the overall patency rate was higher in the MMC side than in the control side $(84.7 \%$ vs $71.8 \%, p=0.004)$. Specifically within the MMC nasal cavities the percentage of stenosis was higher in the subgroup with cottonoid application. Otowick use presented better results mainly in primary cases as in revision cases a comparison cannot be performed due to small sample size. Cottonoids did not present any significant effect in primary cases. All data of endoscopic findings are presented analytically in Table 1. No difference between genders was found on the frontal ostium patency $(p=$ $0.9)$. In addition no difference on the ostium patency was found between younger $(<45 y .0)$ and older $(\geq 45 y$.o.) patients $(p=$ 0.77).

\section{Need for revision surgery}

Overall six patients (nine nasal cavities) needed an additional operation (12.75 \% of patients). Among them six nasal cavities were control sides and three MMC sides (two cottonoid vs one otowick).

Two patients with primary surgery required further surgery (in the first patient the control side, in the second patient both the control and MMC cottonoid side).

In the revision cases, 2 patients with marked osseoneogenesis in the frontal ostium (1 in cottonoid subgroup/1 in otowick subgroup) required an additional operation in both frontal sinuses. Moreover, 2 patients underwent further surgery in their control sides.

No complications or toxic effects were reported regarding the use of MMC in all follow-up assessments.

\section{Discussion}

Endoscopic surgery is the primary approach used today for the surgical treatment of chronic rhinosinusitis. However, frontal 
sinus ostium patency still present difficulties to maintain, and is one of the main causes for revision surgery ${ }^{(1,2)}$. Different techniques and materials (balloon, mitomycin-c, stent) have been used for the prevention of frontal sinus ostium stenosis. Although the local application of MMC is supported by animal and experimental studies ${ }^{(11,12)}$, its clinical value is still debatable especially for the frontal ostium ${ }^{(7,8)}$. This is because clinical studies did not present convincing results ${ }^{(13)}$. In a recent review assessing all rhinological MMC studies between 1991-2009, there appears a favorable short-term effect of MMC on maintaining patency, preventing stenosis, and reducing adhesion formation ${ }^{(6)}$.

The present study tried to assess if a material that deeper covers the area of interest could improve the surgical outcome. The major results of this study are as follows:

1. Two applications of MMC present favorable patency rates of the frontal ostium compared with controls regardless the way of application.

2. A deeper application of MMC using an otowick seems to be a more effective way for the maintenance of frontal ostium patency.

Repetitious application of MMC have been proposed by many authors in experimental and clinical settings as a method for better results, a fact in agreement with our outcome ${ }^{(8,9,11)}$. One intraoperative MMC application seems to be not enough in endoscopic sinus surgery, as even a small bleeding in the surgical field can have a negative impact to local MMC concentration. Except the number of applications, other important factors that can influence the results of MMC application include concentration and dosage, duration and method of application.

As the long-term safety of MMC application within the nasal cavity is not yet established, we have to avoid inadvertent contact of the drug with the adjacent nasal mucosa, applying MMC only onto the area of interest. The otowick provides a more precise and focused application of the drug covering deeper in a complete way the frontal ostium. The need for a deeper application was noticed in a recent case report by Gutierrez and Hopkins in which they applied MMC in a stenosed median frontal drainage through a nasopharyngeal tube trimmed with cottonoids ${ }^{(14)}$. A similar technique has been described in oesophageal strictures, however, is not very precise and standardized ${ }^{(15)}$. Our results show that the use of a foamy material in the frontal sinus can be safe and effective providing an alternative tool for the local drug application.

The material used should be compatible for the injected solution in terms of equal expansion and drug distribution. MMC is diluted in an aqueous solution and otowick has been proven in a study by Clamp that presents significantly different rates of ab- sorption into, and expansion when different drops were used ${ }^{(16)}$. Specifically all aqueous ear drop preparations produced similar high rates of absorption and expansion, however, oil-based ear drop preparations failed to expand the wick and showed poor rates of absorption into it. The length of the otowick should be shortened to $6 \mathrm{~mm}$. This is because the actual size of frontal sinus ostium as described by Lang et al. ranges from 1 to $6 \mathrm{~mm}$ (mean length of $3.08 \mathrm{~mm}$ ) ${ }^{(10)}$.

In revision cases with osteoneogenesis around the frontal ostium, MMC had no favorable results. The presence of osteoneogenesis is considered as a factor of surgical failure ${ }^{(17)}$. It has been suggested that osteitic bone remnants act as an inflammatory nidus, inducing an inflammatory reaction which may contribute to frontal ostium stenosis.

The relatively small sample size of our study does not allow clear conclusions regarding the deeper MMC application into the frontal ostium although it's initial positive results.

It should be noted that none of the patients reported any studies systemic toxicity or adverse effects after sinonasal use of MMC, which is in agreement with a similar study ${ }^{(6)}$. However, for higher concentrations and/or dosages the debate about concentration vs. safety remains to be addressed ${ }^{(18)}$. MMC is currently approved by the European Medicines Agency as an antineoplasmatic agent for certain types of cancer (e.g. gastric and pancreatic adenocarcinoma). Off-label, its use has been documented mainly in ophthalmology (pterygium, trabeculectomy $)^{(19,20)}$, plastic surgery (keloids) ${ }^{(21)}$ and rhinology (dacrocystorhinostomy) $)^{(22)}$. Years of surgical experience in these fields have shown that the concentration used in our study for 5 minutes appears to be safe. None of the studies reported any adverse effects or systemic toxicity of topical MMC when applied for 5 minutes in a maximum concentration of $0.6 \mathrm{mg} / \mathrm{mL}$ (usual range in the literature $0.4-0.5 \mathrm{mg} / \mathrm{ml}$ ) and a maximum dose of $1.5 \mathrm{~mL}$. Although no reports of local toxicity have been reported in rhinology, the ophthalmological literature has documented some serious, even vision-threatening complications. However, this resulted in patients taking MMC as eye drops for several days. In addition, airway obstruction due to exudation reported in some cases of laryngotracheal stenosis and intraoperative MMC application, a fact mainly seen when a quite high concentration was used $(10 \mathrm{mg} / \mathrm{ml})^{(23)}$.

As many issues remain to be addressed regarding the safety of local MMC application, the described technique avoids an unnecessary contact of the drug with larger areas of nasal mucosa providing a more precise and deeper drug delivery. Based on that and regardless the material that surgeons like, we conclude that deeper and precise MMC application may can affect the final outcome significantly. 


\section{Authorship contribution}

IK: study design, surgery, data interpretation, drafting; AC: blinded clinician for data collection, critical review, JC: critical review.

\section{Conflict of interest}

All authors: no conflicts.

\section{References}

1. Senior BA, Kennedy DW, Tanabodee J, Kroger H, Hassab M, Lanza D. Long term results of functional endoscopic sinus surgery. Laryngoscope. 1998; 108: 151-157.

2. Ramadan HH. Surgical causes of failure in endoscopic sinus surgery. Laryngoscope. 1999: 109: 27-29.

3. Philpott CM, Thamboo A, Lai L, Park J, Javer AR. Endoscopic frontal sinusotomy-preventing recurrence or a route to revision? Laryngoscope. 2010; 120:1682-1686.

4. Naidoo Y, Wen D, Bassiouni A, Kenn M Wormald $\mathrm{P}$. Long term results after primary frontal sinus surgery. Int Forum Allergy Rhinol. 2012; 2: 185-190.

5. Chandra RK, Palmer JN, Tangsujarittham T, Kennedy DW. Factors associated with failure of frontal sinusotomy in the early follow-up period. Otolaryngol Head Neck Surg. 2004; 131: 514-518.

6. Karkos P, Leong S, Sastry A, Assimakopoulos A, Andrew S. Evidence-based applications of mitomycin C in the nose. Am J Otolaryngol. 2011; 32: 422-425.

7. Chan KO, Gervais M, Tsaparas Y, Genoway K Manarey C, Javer A. Effectiveness of intraoperative mitomycin $C$ in maintaining the patency of a frontal sinusotomy: a preliminary report of a double-blind randomized placebo-controlled trial. Am J Rhinol. 2006; 20: 295-299.

8. Amonoo-Kuofi K, Lund VJ, Andrews P, Howard D. The role of mitomycin C in surgery of the frontonasal recess: a prospective open pilot study. Am J Rhinol. 2006; 20: 591-594.

9. Konstantinidis I, Tsakiropoulou E, Vital I, Triaridis S, Vital V, Constantinidis J. Intra- and postoperative application of mitomycin C in the middle meatus reduces adhesions and antrostomy stenosis after FESS. Rhinology. 2008; 46: 107-111.

10. Lang J. Clinical anatomy of the nose, nasal cavity and paranasal sinuses. 2nd ed. Stuttgart: Thieme; 1989.

11. Kavuzlu A, Arslan N, Tastan E, Islam A, Usun $H$, Aydogan F. The effects of repetitious topical use of mitomycin C on antrostomy patency in maxillary antrostomy created rabbit model. Eur Arch Otorhinolaryngol. 2011; 268:1597-1603.

12. Rahal A, Péloquin L, Ahmarani C. Mitomycin $C$ in sinus surgery: preliminary results in a rabbit model. J Otolaryngol. 2001; 30: 1-5.

13. Tabaee A, Brown SM, Anand VK. Mitomycin $C$ and endoscopic sinus surgery: where are we? Curr Opin Otolaryngol Head Neck Surg. 2007; 15: 40-43.

14. Gutierrez T, Hopkins C. Safe application of mitomycin C within the nasal cavity. J Laryngol Otol. 2011; 125: 309-310.

15. Heran M, Baird R, Blair G, Skarsgard E. Topical mitomycin $C$ for recalcitrant esophageal strictures: a novel endoscopic/fluoroscopic technique for safe endoluminal delivery. J Pediatr Surg. 2008; 43: 815-818.

16. Clamp PJ. Expansile properties of otowicks: an in vitro study. J Laryngol Otol. 2008; 122 687-690.

17. Lee JT, Kennedy DW, Palmer JN, Feldman M, Chiu AG. The incidence of concurrent osteitis in patients with chronic rhinosinusitis: a clinicopathological study. Am J Rhinol. 2006: 20: 278-282.

18. Hu D, Sires BS, Tong DC, Royack GA, Oda D. Effect of brief exposure to mitomycin $C$ on cultured human nasal mucosa fibroblasts. Ophthal Plast Reconstr Surg. 2000; 16: 119125.
19. Kaufman SC, Jacobs DS, Lee WB, Deng SX, Rosenblatt MI, Shtein RM. Options and adjuvants in surgery for pterygium: a report by the American Academy of Ophthalmology. Ophthalmology. 2013; 120: 201-208.

20. Cheng JW, Xi GL, Wei RL, Cai JP, Li Y. Efficacy and tolerability of nonpenetrating glaucoma surgery augmented with mitomycin $C$ in treatment of open-angle glaucoma: a meta-analysis. Can J Ophthalmol. 2009; 44: 76-82.

21. Sanders KW, Gage-White L, Stucker FJ Topical mitomycin $C$ in the prevention of keloid scar recurrence. Arch Facial Plast Surg. 2005; 7: 172-175.

22. Cheng SM, Feng YF, Xu L, Li Y, Huang JH. Efficacy of mitomycin $C$ in endoscopic dacryocystorhinostomy: a systematic review and meta-analysis. PLoS One. 2013; 13: e62737.

23. McCurdy Hueman E, Simpson B. Airway Complications from Topical Mitomycin C. Otolaryngol Head Neck Surg. 2005; 133: 831-835.

lordanis Konstantinidis

3 Kapetan Kotta str.

Panorama

Thessaloniki 55236

Greece

Tel: +30-697-3229525

Fax: +30-231-093 4888

E-mail:jordan_orl@hotmail.com

\section{Erratum}

In the June 2014 issue of Rhinology the manuscript by Gül et al. entitled: “Cultural adaptation of an olfactory test: the odour in bottle test" originally published in Rhinology 2014; 52: 172-177, both the title and the Isit of authors wer incorrect. This has been corrected in the PDF version on the website. This erratum is to indicate this error and allow correction in Pubmed and other databases.ill The right header is shown here:

\section{Cultural adaptation of an olfactory test: the odour in bottle test ${ }^{*}$}

Aylin Gül, Mehmet Akdağ, Fazıl Emre Özkurt, Beyhan Yılmaz, Engin Şengül, Salih Bakır, İsmail Topçu

Department of Otorhinolaryngology, Dicle University School of Medicine, Diyarbakir 21280, Turkey
Rhinology 52: 172-177, 2014

DOI:10.4193/Rhino13.055

*Received for publication:

May 6, 2013

Accepted: December 13, 2013 